at the Institute of the Arts of the Volyn National University named after Lesya Ukrainka and the National Musical Academy named after. Ukraine: Sat Sciences, etc. O. I. Komenda]. Lutsk. Vol. 5. P. 248-257 [in Ukrainian].

9. Rubinstein Anton Grigorievich // Biographies. The history of the great people URL: http://www.tonnel.ru/?1=gzl\&uid=847 [in Russian].

10. Briniszlavzky, T. (Magyar) zenei élet Kárpátián. Intermix kiady, Uvár. Budapest, 1993. S. 22. [in Hungarian].

11. Victor Ritter Umlauff von Frankwell, Leben und Wirken eines österreichischen Justizmannes. Ein biographisches Denkmal. Vienna: F. Manz \& Comp., 1861. S. 11-149. [in German].

Стаття надійшла до редакції 06.09.2017

УДК $78.03+785$

DOI: 10.31723/2524-0447-2017-25-293-303

Зиновий Павлович Буркацкий

https://orcid.org/0000-0003-1402-9966

кандидат искусствоведения, и.о. профессора, заведующий кафедрой духовых и ударных инструментов

Одесской национальной музыкальной академии имени А. В. Неждановой

Zinoviy.burkatskyy@gmail.com

\title{
ИНСТРУКТИВНЫЕ ЭТЮДЫ В ТВОРЧЕСКОЙ РАБОТЕ ДУХОВОГО ОТДЕЛА ОДЕССКОЙ НАЦИОНАЛЬНОЙ МУЗЫКАЛЬНОЙ АКАДЕМИИ ИМЕНИ А. В. НЕЖДАНОВОЙ
}

Целью работы является рассмотрение инструктивных этюдов, в том числе предложенных автором статьи в составленных им трех сборниках, в их конкретной направленности на выработку тех или иных показателей виртуозной кларнетной техники, что позволяет систематизировать инструктивный материал как средство овладения комплексом актуальных технически-смысловых позиций в игре кларнетиста-профессионала. Методологической базой исследования является современный интонационно-исполнительский подход, начало которого положено в работах Б. Асафьева и получившего развитие в музыковедении Украины, в том числе в работах Н. Давыдова, В. Апатского, И. Котляревского, И. Ляменко, К. Мюльберга и др. Особо выделяем жанрово-типологический и сравнительно-стилевой методы анализа. Научная новизна исследования обеспечивается оригинальностью теоретико-методической позиции автора, обобщающего свой творчески-исполнительский опыт, а также крупнейших мастеров одесской кларнетной школы, в ракурсе предложения комплекса виртуозных навыков в концертных этюдах, при-

(c) Буркацкий 3. П., 2017 
нимающих на себя функции «малой энциклопедии» актуальных показателей мастерства кларнетиста. Выводы. Этюды обычно имеют целью развитие ряда технических навыков - специальных в каждой отдельной пьесе, но существует суммированние их (по листовскому приниипу!) в одном этюде как в «малой технической энииклопедии». И такого рода «суммирование» смысловых и технических задач находим в концертных этюдах, в том числе в авторских этюдах, например, Этюдах И. Оленчи$\kappa a$, апробированных в успешных выступлениях одесситов-кларнетистов на ответственных международных конкурсах.

Ключевые слова: жсанр этюда, инструктивный этюд, концертный этюд, виртуоз, исполнительский стиль, выразительность кларнетной игры.

Burkackiy Zinoviy, Ph.D. in the History of Art, acting Professor, Head of the department of wind and percussion instruments of Odessa National A. V. Nezhdanova Academy of Music

Instructive etude in the creative work of the wind department of Odessa $\mathrm{Na}$ tional A. V. Nezhdanova Academy of Music

The Purpose of the work is consideration technical etude, including offered by author to articles in formed by him three collections, in their concrete directivity on production that or other factors of the virtuoso clarinet technology, that allows to systematize technical material as facility of the mastering by complex actual technically-semantic position in play of the clarinetist-professional. The methdological base of the study is modern intonation performance approach, begin which mortgaged in work of $B$. Asafiev and which has got the development in musicology of the Ukraine, including in work N. Davydov, V. Apatskij, I. Kotljarevskij, I. Ljashenko, K. Mulberg and others. Specifically select genre-typical and relatively-style methods of analysis. Scientific novelty of the study is provided by originality theorist-methodical position of the author, generalizing its creative-performance experience, as well as the most largest masters of the Odessa clarinet school, in for shortening of the offer of the complex virtuoso skill in concert etude, taking over functions «small encyclopedia» of actual factors skill clarinetist. Conclusions. The etudes usually aim the development of the row technical skill - special in each separate play, but exists the summation their (on Liszt principle!) in one etude as in «small technical encyclopedia». And such sort «summation» semantic and problems of engineering find in concert etude, including in author's etude and above named Etude I. Olenchik, approved in successful appearances clarinetists of Odessa on responsible international contest.

Keywords: genre of the etude, technical etude, concert etude, virtuoso, performance style, expressiveness of the clarinet play. 
Буркацький Зіновій Павлович, кандидат мистецтвознавства, в.о. професора, завідувач кафедри духових та ударних інструментів Одеської національної музичної академії імені А. В. Нежданової

Інструктивні етюди в твориій роботі духового відділу Одеської національної музичної академії імені А. В. Нежданової

Метою роботи є розгляд інструктивних етюдів, у тому числі запропонованих автором статті в складених ним трьох збірниках, у їх конкретній спрямованості на вироблення тих або інших показників віртуозної кларнетової техніки, що дозволяє систематизувати інструктивний матеріал як засіб оволодіння комплексом актуальних технічно-значеннєвих позицій у грі кларнетиста-професіонала. Методологічною базою дослідження є сучасний інтонаційно-виконавський підхід, початок якого закладений в роботах Б. Асаф'єва і який одержав розвиток у музикознавстві України, у тому числі в роботах М. Давидова, В. Апатського, I. Котляревського, I. Ляшенка, К. Мюльберга й ін. Особливо виділяємо жанрово-типологічний та порівняльно-стильовий методи аналізу. $\mathbf{H a -}$ укова новизна дослідження забезпечується оригінальністю теоретикометодичної позиції автора, що узагальнюе свій творчо-виконавський досвід, а також досвід найбільших майстрів одеської кларнетової школи, у ракурсі пропозиції комплексу віртуозних навичок у концертних етюдах, що приймають на себе функції «малої енциклопедії» актуальних показників майстерності кларнетиста. Висновки. Етюди звичайно мають на меті розвиток ряду технічних навичок - спеціальних в кожній окремій n'єсі, але існує підсумовування їх (за лістівським принципом!') в одному етюді як в «малій технічній енциклопедї̈. I такого роду «підсумовування» виразних і технічних завдань знаходимо в концертних етюдах, у тому числі в авторських етюдах, наприклад, Етюдах I. Оленчика, апробованих в успішних виступах одеситів-кларнетистів на відповідальних міжкнародних конкурсах.

Ключові слова: жанр етюду, інструктивний етюд, концертний етюд, віртуоз, виконавський стиль, виразність кларнетової гри.

Актуальность. Использование этюдов в учебной и концертно-исполнительской деятельности музыканта-кларнетиста позволяют уделить специальное внимание тому отбору, который осуществляет художественно-педагогическая практика в конкретном учебном заведении, в том числе профессионалами отделения духовых инструментов Одесской национальной музыкальной академии им. А. В. Неждановой. Специфика методических и методологических установок ведущих специалистов названного отделения определена во многом тем, что руководство осуществляет один из выдающихся исполнителей и педагогов Украины К. Мюльберг - заслуженный деятель искусств Украины, профессор, кандидат искусствоведения. По ини- 
циативе профессора К. Мюльберга профессиональные наблюдения автора статьи были апробированы экспериментами в русле разработанного им исследования техники игры кларнетиста [4]. Эти последние осуществлены с целью демонстрации преимуществ методики работы над этюдами в процессе воспитания виртуозов. В свою очередь методический выбор определил работу над сочинениями С. Розанова, Б. Дикова, П. Суханова, А. Федотова. Особенно выделяем композиции первого, поскольку наши методически-творческие разработки осуществлялись в русле теоретического осмысления педагогических наработок [5].

Целью работы является рассмотрение инструктивных этюдов, в том числе предложенных автором статьи в составленных им трех сборниках, в их конкретной направленности на выработку тех или иных показателей виртуозной кларнетной техники, что позволяет систематизировать инструктивный материал как средство овладения комплексом актуальных технически-смысловых позиций в игре кларнетиста-профессионала.

Изложение основного материала. Известно, что этюды как инструктивный учебный материал кларнетиста появились в первых сборниках «Школ для кларнета» в начале XX столетия, например, в «Школе» Ф. Блатта. В XIX и XX веках европейские школы кларнета были представлены Г. Клозе и П. Жан-Жаном во Франции, К. Берманом в Германии. Из Италии пришли этюды А. Маньяни, Габучи, из Чехии - И. Кратохвила, М. Этлика, А. Долезала, из Польши Л. Куркиевича, Л. Видеманна, Й. Мадея, из Болгарии С. Димитрова, из Венгрии - Вакзи. В России сформировался ряд музыкантовкларнетистов, писавших этюды, - С. Розанов, Б. Диков, А. Володин, А. Штарк, Р. Штарк, а в Украине - С. Рыгин, В. Гурфинкель, В. Носов, И. Оленчик, автор статьи.

Указанные авторы этюдов имеют преимущества перед другими, с нашей точки зрения, в том смысле, что овладение заложенными в их пьесах приемами-умениями могут гарантировать выход на высшую ступень кларнетовой техники исполнения произведений высокого художественного смысла. Таковы результаты ряда выступлений наших воспитанников на конкурсах национального и международного значения. Так, студент IV курса В. Ж., лауреат международного конкурса в Молдове, осушествлял тренинг на материале этюдов, предложенных автором работы. Аналогична ситуация с выступлениями студента II курса Д. Р., готовившего конкурсные программы в мето- 
дическом русле, определенном сборниками этюдов, составленных автором исследования. Получают признание во всеукраинских и городских концертных мероприятиях и конкурсах-смотрах выступления студентов Ю. Г., Ю. Р. и других, прошедших школу совершенствования кларнетовой игры по указанным сборникам этюдов.

Отбор этюдов в эти сборники осуществлялся, как отмечалось выше, по итогам апробации коллективного опыта поколений музыкантов, воспитанных в Одесской музыкальной академии, а также индивидуальным выбором, осуществляемым наиболее авторитетными музыкантами духовой кафедры вышеназванного музыкального вуза. Этих сборников было выпушено три; в дальнейшем описании называем их сборник № 1, сборник № 2, сборник № 3. Мы акцентируем в данном отборе иерархию технических приемов, ценных по тем или иным показателям в профессиональном совершенствовании кларнетиста.

Этюды В. Гетмана, С. Розанова, В. Петрова направлены на овладение подвижностью в legato при неудобных интервальных переходах в быстром темпе. Этот способ работы дает свои положительные результаты при исполнении классических композиций типа «Кларибель» С. Бозза. Этюды А. Перье, С. Розанова, Р. Гофмана, К. Милле, предназначенные для отработки пунктирных ритмов, составляют незаменимое средство совершенствования техники кларнетной концертной игры, например, «Пьеса в соль миноре» Ж. Бара. Аналогичный ритмический рисунок, но в более живом движении, имеем в этюдах Р. Штарка.

Этюды П. Жан-Жана, А. Маньяни позволяют отрабатывать технику мелизмов в тональностях с большим количеством знаков альтерации, сложными метрами, группировкой, размерами, внеключевыми знаками, модуляциями и др. Этюд В. Гурфинкеля, ориентированный на овладение мелизматикой, запечатлевает фактурные тенденции фольклористичных произведений современности. Те же приемы имеют место в оригинальных композициях румынского композитора Т. Олаха и россиянина Э. Денисова, написавших Сонаты для кларнета-соло. Удачным является этюд на мелизмы Р. Гофмана, в котором тренирующемуся дана возможность отработать короткие форшлаги и морденты. Напомним, что мелизмами называют мелодические фигуры, которые «украшают» отдельные звуки мелодии. К мелизмам относятся короткие форшлаги, морденты, группетто и трели. 
Выдающиеся московские музыканты С. Розанов и Б. Диков предложили способ работы над «скрябинской» ритмофигурой «полета», в которой в особенности трудно дается объединение пунктира и триольных групп. Такой тип ритмики у духовых в целом и в частности у кларнета находим в значительном количестве произведений не только А. Скрябина, но и у Р. Штрауса, П. Хиндемита и других композиторов XX ст.

Украинские авторы этюдов, знатоки проблем кларнетной техники - В. Гурфинкель, В. Гетман, И. Оленчик, В. Носов - предлагают оригинальные находки в тренировочном использовании приемов с учетом стилевого контекста музыкального произведения. Так, В. Гетман написал свой этюд для отработки ритмического чувства в несимметричных метрах с переменными ритмо-группами. Автор опирается на старинную «кантовую формулу», общая употребительность которой предоставляет будто бы «указатель» в объединении непривычных, довольно сложных группировок с традицией.

Та же цель - чувствительность к непривычным ритмическим изменениям групп в несимметричных размерах - обрисовывается в этюдах известного болгарского кларнетиста С. Димитрова. Как известно, болгарские ритмы с точки зрения Б. Бартока воплощают наиболее актуальную и наиболее сложную сторону ритмики XX ст. Ведь именно пьесами «в болгарских ритмах» Б. Барток заканчивает свой «Gradus ad Parnasum» - VI тетрадь «Микрокосмоса». В Этюдах С. Димитрова отрабатываются сложные метры, размеры и группировка, которые употребительны и в современном кларнетном обиходе.

Этюды А. Штарка, Б. Дикова, Р. Гофмана направлены на развитие умений игры хроматических последовательностей в различных тональностях, темпах, динамике, и выстроены нами по возрастающей сложности.

Этюды Р. Штарка, Г. Вахеса также предлагаются нами для освоения необычайно важного, часто встречающегося в произведениях для кларнета штриха staccato. Повышенное внимание к исполнению этого штриха определено тем, что здесь требуется точность координации движений языка и пальцевого аппарата музыканта-кларнетиста. Исполнение этюдов Л. Видемана, И. Мюллера, Г. Клозе, П. Мимара, предлагающих упражнения на различную интервалику, особенно на широкие интервалы в legato, составляет большую трудность, как для молодых музыкантов, так и для музыкантов-профессионалов, и по- 
этому особенно необходимо при работе над произведениями любых жанров и стилей.

Этюды Л. Видемана, Г. Клозе заключают в себе приемы отработки арпеджированных последовательностей. По сравнению с интервальной и репетиционной техникой, техникой мелизмов арпеджио не столь трудны для исполнителя, хотя весьма важны и часто употребляемы и поэтому требуют соответствующих умений и навыков. Этюды Г. Клозе, Л. Видемана отобраны нами для освоения смешанных видов техники. В них совмещены все перечисленные выше виды техники одновременно, т. е. эти этюды предполагают быстрое психологическое и техническое переключение исполнителя, что соответственно требует его повышенного внимания и мастерства. Подобные этюды наиболее близки к концертным произведениям, так как отличаются техническим и образным разнообразием и помогают исполнителю выразительнее и точнее воплотить намеченные композитором характер и эмоциональное качество образа.

Этюды Г. Клозе и Р. Штарка представляют собой удачную подборку приемов осуществления гаммообразного движения, весьма часто применяемого академическими, романтическими и современными композиторами. Этюды Л. Видемана, 3. Буркацкого, И. Оленчика, Г. Вахлса, Р. Штарка, А. Маньяни специально были созданы для отработки сложной аппликатуры, штрихов и видов техники (пассажной, гаммообразно-моторной) методом многократного повторения мелодической (ритмической) фразы и репетиционной их отработки.

Эти и другие этюды были предложены студентам музыкального вуза для демонстрации технических возможностей и дальнейшего их усовершенствования. Эксперимент предусматривал анкетирование учеников, которым было предложено выучить незнакомые этюды самостоятельно, но в присутствии членов комиссии. Продолжительность подготовки одного этюда составляла 1 час. Подобные акции проводились на протяжении двух лет, в них приняло участие свыше 20 студентов-кларнетистов.

Члены комиссии внимательно наблюдали за процессом работы музыкантов и анализировали его, записывая эти наблюдения в анкету. После самостоятельной работы студента над этюдом члены комиссии давали необходимые советы индивидуально каждому участнику эксперимента - на какой именно вид техники и штрихов следует обратить больше внимания студенту, указывали на подбор правильной аппликатуры, на темпы, при которых целесообразно изучать новые 
этюды. Особое внимание обращалось на работу над сложными фрагментами этюдов и необходимое количество повторов при их изучении, с постепенным увеличением темпа от медленного, учебного до указанного автором темпа.

Мы обнаружили одну из наиболее слабых сторон в процессе освоения инструктивного материала - это недостаточность усвоения техники мелизмов, затрудненность переведения данного навыка с уровня представления на уровень навыка игры исполнения. Ведь большое количество концертов, сонат, ансамблевых и оркестровых произведений не может обойтись без стилистически правильного выполнения мелизмов в различных стилях, эпохах и направлениях. Точное исполнение мелизмов раскрывает стилистические особенности и художественную выстроенность целого произведения (последовательное описание данного процесса апробации этюдного материала в практике дано в статьях автора исследования [2; 3].

«Жемчужины» кларнетного репертуара, в которых авторы целенаправленно использовали технику мелизмов как яркое средство художественной выразительности - это произведения: Э. Боцца «Буколика»; Л. Шпор Концерты № 1, 2, 3; К. Вебер «Концертино», Концерты № 1, 2; Дж. Россини «Интродукция, тема и вариации»; Э. Габлер Концерт № 1 и многие другие произведения. Мелизматика в инструментализме - эта мало разработанная тема, которая требует дальнейшего изучения. Корни этой техники были заложены в вокале, в приемах «украшений» звука, ценного своей тоновой устойчивостью и значимого в запечатлении высокой абстракции выражения.

Украшение словесного текста пением находим еще в античные времена, что и составило базу так называемой «вокальной риторики», положенной в основание риторики инструментальной. Еще древние индейцы пользовались «кампо» - нотой, которая создает эффект «дрожи», ее знак в тексте очень характерен и по запечатлевающему ее рисунку. Мелизмы в современных нотных текстах также тяготеют почти к иероглифической наглядности, поскольку в основе их - иконические знаки, знаки-изображения направления мелодии. И если более ранней является запись мелизмов в нотах по вертикали, то есть в воспроизведении «приставленности» этого оборота к конкретной ноте, то позднее возникло обозначение по горизонтали, предполагающее в восприятии музыканта «параллелизм» представлений относительно основного тематического хода и сопровождающей его риторической мелизматической фигуры. 
А. Бейшлаг в своей работе «Орнаментика в музыке» пишет, что старинный культовый напев описывался как «пышно украшенный». И если Платон был удовлетворен тем, что его ученик-грек умел выполнять мелодию просто, то от учителя он требовал более «разрисованного» выполнения $[1,5]$. Но это - специальная тема, неизбежно затрагиваемая в аспекте усвоения техники приема мелизмов, поскольку владение этими оборотами неотделимо от смыслового решения разделов и самого целого музыкальных композиций. Проведенный эксперимент «от логики жизни искусства» обратил внимание на технический прием, словесная терминология которого («украшение»!?) настраивает учеников по отношению к нему как к чему-то «вспомогательному» и отнюдь не главному в техническом обеспечении как таковом.

Судя по откликам, которые были получены и которые поступают до сегодняшнего дня от преподавателей, где по месту их работы проходят апробацию сборники этюдов, использование этих последних неизменно дает положительный результат. Предлагаются рекомендации по типографскому оформлению издания трех сборников на разные виды техники и штрихов. Очень важным, с нашей точки зрения, является подбор этюдов для студентов с разной степенью профессиональной подготовки по видам техники и штрихов. Как показывает опыт, эта дифференциация трудностей наиболее сложна для наших студентов. Педагогическая помощь необходима конкретно тому или иному ученику с конкретной же целевой установкой на преодоление технической трудности.

Выводы. Подводя итоги работы над сборниками и их воплощением в практику подготовки студентов, акцентируем такие положения.

Во-первых, в сборниках целесообразно отбирать по 5, 6, 7 вариантов этюдов в движении от простого к сложному по каждому виду техники и штриха. При таком размещении материала имеется возможность отбора этюдов специально для молодых музыкантов и музыкантов-профессионалов.

Во-вторых, предлагаем для гармоничного технического развития специалистов-кларнетистов не «засиживаться» на одном виде техники или штриха при подготовке в силу комплексности навыков и психологии освоения трудностей игры. Необходима установка на всеобъемлющий характер технического развития, умение «быть в форме», что вызывает интенсивность приобретения новых навыков и умений «по смежности» технически приобретенного и получаемого навыка. 
В-третьих, музыканту-кларнетисту, довольно часто находящемуся в режиме преодоления сложных, «неудобно-разнообразных» трудностей в учебной, концертной, оркестровой деятельности, необходимо установить для себя принцип работы по индивидуальному графику, смысл которого - исключительная гибкость тренировки в выборе и предмета, и целеполагания.

Не представляемо на сегодня звучание симфонических, духовых, народных, джазовых оркестров и разнообразных ансамблей без участия в них кларнета, незаменимого по разнообразию тембра, диапазона, яркости звучания, возможностям нюансировки в согласованности с другими деревянными духовыми инструментами. А это все - стилистически самостоятельные качества исполнения, подготовка к которым требует особого режима работы и выбора для этой работы соответствующего этюдного материала.

Не случайно современная музыкальная наука и, главное, творческая практика утверждают: этюды обычно имеют целью развитие ряда технических навыков - специального в каждой отдельной пьесе, но также суммирование их (по листовскому принципу!) в одном этюде как в «малой технической энциклопедии». И такого рода «суммирование» технических задач находим в концертных этюдах, в том числе в авторских, например, Этюдах И. Оленчика, апробированных в успешных выступлениях одесситов-кларнетистов на ответственных международных конкурсах.

\section{СПИСОК ЛІТЕРАТУРИ}

1. Бейшлаг А. Орнаментика в музыке. Москва, 1978. 320 с.

2. Буркацький 3. Експериментальність вибудови етюдних кларнетових збірників за їх місцем у самостійній роботі виконавця. Науковий вісник Одеської державної консерваторії ім. А. В. Нежданової. Одеса, 2002. Вип. 3. С. $214-$ 222.

3. Буркацький 3. Про специфіку функціювання етюдів в учбовій діяльності кларнетиста. Науковий вісник Одеської державної консерваторії ім. А. В. Нежданової. Одеса, 2001 . Вип. 2. С. 189-198.

4. Мюльберг К. Исследование некоторых компонентов техники кларнетиста: автореф. дис. ... канд. искусствовед.: 17.00.03. Москва: ГМПИ им. Гнесиных, 1980. 23 с.

5. Розанов С. Школа игры на кларнете. Москва: Музыка, 1958. 162 с.

\section{REFERENCES}

1. Beiszhlag A. (1978) Ornamentation in music. Moscow [in Russian)]. 
2. Burkackiy Z. (2002) Eksperimental character of straightening etude clarinet collection up on their placeinin dependent working of the performer. Naukoviy visnyk Odeskoji derzhavnoi conservatorii imeni A. V. Nezhdanovoi. Issue 3. Odesa. P. 214-222 [in Ukrainian].

3. Burkackiy Z. (2001) About specifics of the operation etude in scholastic activity of the clarnetist. Naukoviy visnyk Odeskoji derzhavnoj iconservatorij iimeni A. V. Nezhdanovoji. Issue 2. Odesa. P. 189-198 [in Ukrainian].

4. Mulberg K. (1980) Study some component technology of the clarinetist. Extended abstract of candidate's thesis. Moscow, GMPI im. Gnesinyh. [in Russian].

5. Rozanov S. (1958) School of the play on clarinet. Moscow, Muzyka. [in Russian].

Стаття надійшла до редакції 14.06.2017

УДК 78.071.2+781.6

\author{
Олеся Григорівна Небога \\ https://orcid.org/0000-0001-8731-4130
}

аспірантка третього року навчання кафедри мистецтвознавства

Кивського національного університету культури та мистецтв, викладач Київського інституту музики імені Р. М. Гліера lesigor@rambler.ru

\title{
КИЇВСЬКА ВОКАЛЬНА ШКОЛА У ПЕРШІЙ ПОЛОВИНІ XX ст.
}

\begin{abstract}
Мета статті полягає у спробі на основі аналізу методів діяльності представників київської вокальної школи з'ясувати їх внесок у розвиток вітчизняного вокального мистецтва. Методологія дослідження - застосовано метод історизму, що полягає в еволюційному аспекті побудови дослідження. Окрім иього застосовано структурний та системний методи, як загальнонаукові, при описі існуючих концепцій наукового осмислення школи та методу кожного з викладачів, та компаративний - задля їхнього співвідношення. Наукова новизна проведеного дослідження полягає у систематизації сучасних концепцій осмислення київської вокальної школи першої половини XX століття та у розгляді крізь їхню призму процесу становлення та розвитку. Висновки. На підставі проведеного дослідження оцінено внесок київських педагогів з сольного співу розвиток професійної вокальної освіти на теренах України. Перша половина XX ст. характеризується розвитком професійного українського вокального мистецтва. У цей час закладаються методологічні засади вокального мистецтва, формується професійна київська вокальна школа. Значний внесок у формування професійного вокального мистеитва ХХ ст.
\end{abstract}

(C) Небога О. Г., 2017 